\title{
The formation of microbiots in the body of primates and the provision of their diets with a balanced ratio of macro- and micronutrients
}

\author{
N.V. Gaponov ${ }^{1,2, *}$, and $O . G$. Loretts ${ }^{3}$ \\ ${ }^{1}$ All-Russian Lupine Scientific Research Institute - Branch of the FSBS Institution «Federal Williams \\ Research Center of Forage Production and Agroecology», p/o Michurinskiy, Berezovaya str., 2, 241524 \\ Bryansk region, Russia \\ ${ }^{2}$ FSBI Scientific «Research Institute of Medical Primatology», World st., 177, 354376 Krasnodar \\ Territory, Sochi, Russia \\ ${ }^{3}$ Ural State Agrarian University, 620075 Yekaterinburg, Russia
}

\begin{abstract}
This article presents studies of the formation of symbiotic primitive microbionts and the balancing of macro- and micronutrients of their feeds. To date, more than 20 thousand diverse physiologically active macro- and micronutrients have been isolated and characterized from feed and food products. For a long time, it was believed that the only source of a large number of nutrients is only feed and food. However, experiments convincingly showed that the symbiotic intestinal microflora also takes an active part in the endogenous synthesis and recycling of many macro- and micronutrients. At the same time, the use of the probiotic complex Bactistatin and fish meal did not adversely affect the hematological and biochemical parameters of the blood of experimental monkeys, all indicators were within the physiological norm. And testing the experiment on a larger population, under conditions of enclosure, allowed to establish a reduction in the cost of feed and nutrients in experimental primates and to prove the economic feasibility of using the studied ingredients from the point of view of profitability of feed production and primate content.
\end{abstract}

\section{Introduction}

Phylogenetically, monkeys are closer to humans than other laboratory animals, and in research they are the best experimental subjects for modeling and studying various human diseases and prophylactic agents. A number of human diseases can be reproduced only on primates, and many pharmacologically active compounds exhibit therapeutic effects on monkeys, to the same extent as on humans $[15,16,19]$. Since primates are fed according to diets and feeds close to farm animals and humans. And the structure of microflora is close to humans, this circumstance provides a unique opportunity to study the processes of digestion in the body of primates and extra-polish the results of research, with minimal correction, into

\footnotetext{
* Corresponding author: nv.1000@bk.ru
} 
human practice. Therefore, the study of the influence of symbiotic microbiota, macro- and micronutrients on primates is of great scientific importance for the study of various ways of good nutrition in humans $[2,4,6]$.

Macro- and micronutrients of human food and animal feed, serve as a source of energy for the vital activity of the body. The largest amount of chemicals enters the body from the external environment, in the form of food and feed, and the more fully the needs of the body are satisfied, the higher the nutritional value of food and feed. Together, they are necessary for the body to restore substances destroyed in the process of dissimilation. At the end of the last century, the famous academician Chebotarev V.F. argued that nutrition is practically the only means that prolongs the species belonging of life by $25-40 \%$. This is confirmed by epidemiological studies conducted in the United States, which show that $68 \%$ of all deaths are the result of diseases associated with "malnutrition" [9].

According to the well-known expression of I.P. Pavlova, "concern for our daily bread dominates over all phenomena of human life." This expression has an important conceptual meaning that for the normal life of a person, the coordinated work of the physiological and regulatory systems of his body, it is necessary to timely provide numerous functional ingredients of exogenous and endogenous origin. Of the 107 chemical elements discovered by science, the body needs $22-25$, called biogenic. Four of them - C, O, H, N - make up the bulk of food, feed and animal body (95-98\%). Each of the other elements accounts for from $1-2 \%$ to millionths of a percent. A wide variety of compounds are formed from nutrients in the body. All compounds, similar in terms of the same name of elementary composition, structural organization and functional properties, are combined into groups of macro - and micronutrients. These ingredients are building and energetic materials, precursors or obligatory participants in the synthesis, decay and work of more than 2.5 million different biomolecules that make up the organs and tissues of the human body, and mediators that regulate their normal activity $[9,12,5]$. The most balanced in terms of macro- and micronutrients are animal feeds, such as fishmeal. It is the most valuable source of protein and micronutrients. Fishmeal protein is rich in lysine and other essential amino acids and has a high biological value and digestibility. It has been found that the protein of fishmeal is absorbed by animals much better than the protein of vegetable feed. Experience shows that fishmeal added to animal feed increases the efficiency of using other feeds that are poor in protein and fat; the use of fishmeal in the composition of feed helps to accelerate growth and improve their general condition [11, 18, 21].

As a result of biochemical studies in fish feed products, the so-called protein factor (AR), which is necessary for the assimilation of vegetable protein by animals, vitamin $\mathrm{B}_{12}$ and other water-soluble B vitamins, including riboflavin and pantothenic acid, has been found, which has a strong influence on the growth and development of animals. In this regard, fish feed meal is not only a source of complete animal protein, but also a catalyst in biochemical processes. First of all, we are talking about a surprisingly wide complex of natural substances and minerals that are contained in fish meal: this is phosphorus (almost all seafood is rich in it), as well as calcium, a whole set of amino acids, iodine, selenium, as well as vitamins A, D and group B. Each of these elements has its own beneficial properties. Thanks to which, digestion processes are improved, and immunity is strengthened. In terms of the content of digestible protein, fishmeal takes one of the first places among feed products. So, $1 \mathrm{~kg}$ of fishmeal contains at least $535 \mathrm{~g}$ of digestible protein. Therefore, animals receiving fishmeal are less susceptible to diseases, and due to the optimal ratio of amino acids in the composition of fishmeal, young animals develop faster, maintain immunity and reduce stress. Fishmeal is considered a valuable remedy against goiter diseases, since it contains iodine in the form of organic compounds. For example, cod oil contains 4.5 to $15.2 \mathrm{mg}$ per $\mathrm{kg}$ of fat $[8,16,17]$. 
Since the human and animal organism is a complex symbiotic community of numerous eukaryotic, prokaryotic cells, viruses and archaebacterias. In which the total number of somatic and germ cells reaches 1 trillion, microbial cells over 100 trillion, the relationship between the host and its microbiont is the main factor influencing the growth, development, and health of humans and animals. Accordingly, the degree of assimilation of nutrients by the body depends on the state of its intestinal microbionts. For the formation of microbionts of the gastrointestinal tract of primates, it is advisable to use probiotic complexes, one of which is Bactistatin $[1,13]$.

Bactistatin is a Russian biologically active additive, which is a lyophilized filtrate of the culture liquid of Bacillus subtilis strain No. 3, containing lipolytic and proteolytic enzymes sorbed on zeolite. Oral administration normalizes the microbial ecology of the digestive tract, has an immunomodulating and detoxifying effect [1].

The use of such drugs for the individual formation of a symbiotic microbiont and optimal balancing of animal feed rations and human nutrition with macro- and micronutrients will compensate for the effects of the expression of polymorphic genes that are unfavorable to health, and, conversely, optimize molecular information exchange between all cells of the body, epigenomic control and implementation. those allelic genes that provide better adaptation of the body under normal conditions, under stress and in extreme conditions [12, $14,20]$.

It has been established that the normal intestinal microflora of different species of lower Asian and African monkeys is represented by different taxonomic groups of microorganisms and, in terms of qualitative and quantitative indicators, approaches the microflora of a healthy person. As part of the study of the natural infection of helicobacteriosis, it was found that in the mucous membrane of the stomach and duodenum of monkeys by the PCR (polymerase chain reaction) method, there is determined a fairly high percentage of $\mathrm{H}$. pylori infection. H. pylori DNA contains the ure (36.9\%), vac A (21.9\%), cag A (6.2\%) genes, as well as their various combinations. Despite the high percentage of H. pylori DNA detection, unlike humans, monkeys practically do not have ulcerative lesions of the stomach and duodenum, as well as stomach tumors. The process is limited to inflammatory changes of varying severity. This is probably due to the fact that genes markers of H. pylori pathogenicity in monkeys are 10 times less common than in human strains [2].

Therefore, taking into account the anatomical and physiological similarity of monkeys with humans, their phylogenetic proximity, which makes it possible to study the digestion processes of both animals and humans, makes it promising to use primates as laboratory animals to study the characteristics of human nutrition and animal feeding. The most popular for such biomedical research are the rhesus monkeys. (Macaca mulatta) [16].

Considering the above, the purpose of the study was; to establish the possibility of replacing expensive, high-protein feeds of animal and plant origin with fishmeal, ensuring the maximum balance of macro- and micronutrients. To study the effect of Bactistatin on the formation of symbiotic microbionts, hematological, biochemical parameters of the blood of primates and the determination of the coefficients of digestibility of nutrients in diets of male rhesus monkeys.

\section{Materials and methods}

To implement the intended goals of the experiment, scientific studies were carried out on male rhesus monkeys. The experiments were carried out in vivar conditions on the basis of the Federal State Budgetary Scientific Institution "Research Institute of Medical Primatology". In the vivarium, experiments were carried out to determine the digestibility of 
nutrients and to determine the coefficients of digestibility. For this, the primates were divided into three groups using the method of pairs of analogs, a control group and two experimental ones. After the end of the physiological experiments, the results were tested on a larger livestock in the conditions of an open-air cage [7, 10,21].

In the control group, feeding of primates was carried out with full-feed granulated feed with unlimited access to automatic drinkers. For the experiment, a complete granulated compound feed was produced at the production site of the "Research Institute of Medical Primatology" [5, 6, 21]. In which wheat accounted for $21.4 \%$ of the energy nutritional value. The share of soybean meal in the structure of compound feed accounted for $17.42 \%$. Sunflower cake made up $13.83 \%$. A significant part of the energy of the diet falls on milk, skim powder and it is $14.39 \%$. The diet of the control group was balanced by the introduction of sunflower oil, which amounted to $0.8 \%$. The remaining $32.16 \%$ of energy came from corn gluten $11.24 \%$, corn $13.35 \%$, egg powder $3.3 \%$ and sugar $4.27 \%$.

The primates of the second experimental group received complete feed, which was identical in structure and nutritional value to the control group. But, in addition to compound feed, in order to form a symbiotic microbiont, primates received, as a biologically active additive, the probiotic complex Bactistatin, in an amount of $3 \mathrm{~g} /$ head per day.

In the primates of the third experimental group, in order to maximally positively balance the feeding diet in terms of macro- and micronutrients, in the structure of the diet in terms of nutritional value, the following components were replaced with fish meal: skimmed milk powder by $100 \%$, sunflower meal by $10.00 \%$, egg powder $70 \%$, corn gluten $2 \%$ in total in the structure of the diet of the sixth experimental group fish meal was $18 \%$.

In groups, for setting up the experiment, primates were selected at the age of 7-15 years, as a result, the total number of rhesus monkeys in the experiment was 15 heads, 5 heads per group, respectively. The experiment lasted 35 days. The experiment scheme is presented in Table 1.

Table 1. Scheme of the experiments.

\begin{tabular}{|c|c|c|}
\hline Groups & $\begin{array}{c}\text { Number of } \\
\text { animals }\end{array}$ & Feeding conditions \\
\cline { 3 - 3 } & & Macaca mulatta at the age of 7-15 years \\
\hline $\begin{array}{c}\text { I } \\
\text { Control }\end{array}$ & 5 & Complete feed (CF) \\
\hline $\begin{array}{c}\text { II } \\
\text { Experimental }\end{array}$ & 5 & CF + Bactistatin (3 g / kg fat) \\
\hline $\begin{array}{c}\text { III } \\
\text { Experimental }\end{array}$ & 5 & CF-(18\% fish flour) \\
\hline
\end{tabular}

Experiments on animals were carried out in accordance with the requirements of the order of the Ministry of Health of the Russian Federation No. 267 of June 19, 2003 "On the approval of the rules of laboratory practice", orders of the Ministry of Health of the USSR No. 742 of November 13, 1984 "On the approval of the rules for carrying out work with the use of experimental animals" and No. 48 of January 23, 1985 "On the control of work using experimental animals", ethical standards set out in the Laboratory Practice Guidelines (GLP), the Declaration of Helsinki (2000) and European Community Directives 86/609EEC

During the research, the following materials and indicators were taken into account and controlled:

- zootechnical - safety, live weight in general for experience, feed, nutrient and energy costs.

- physiological and biochemical - the chemical composition of feed, feces, metabolic energy, venous blood, blood serum. 
Blood was taken from monkeys before the start of the experiment and 35 days after the end of the experiment. All blood samples $(2.5-3.0 \mathrm{ml})$ were taken from the ulnar or from the femoral vein of animals on an empty stomach and stabilized with a heparin solution. Laboratory studies of the blood of animals were carried out on a Beckman Coulter, USA, CoulterAcT 5diffCP automatic hematological analyzer. In order to study the effect of dietary supplements on hematological parameters, we determined the level of erythrocytes, leukocytes, platelets, hemoglobin concentration, hematocrit, average erythrocyte volume, erythrocyte anisocytosis, erythrocyte sedimentation rate (ESR). ESR was determined by the Panchenkov method.

Blood serum was obtained according to the standard method. The resulting blood was kept in a thermostat at $37^{\circ} \mathrm{C}$ for $30 \mathrm{~min}$, then centrifuged for $15 \mathrm{~min}$ at $2000 \mathrm{rpm}$. Serum without hemolysis was used in the work. Biochemical analysis of blood serum parameters was performed within 2-3 hours after blood sampling. Biochemical parameters were determined using standard kits from High Technology, Inc on a semi-automatic analyzer BioChem SA: total protein, glucose, total bilirubin, calcium, phosphorus.

The balance experiment, to determine the digestibility of nutrients in the diet, was divided into two periods. Preparatory ( 5 days). The goal, which is to exclude the influence of previous feeding and to accustom the primates to the conditions of cage keeping. The accounting (experimental 5 days) during this period carried out a thorough accounting of the consumed feed, excreted excrements. The feeding schedule of primates in the experimental period was the same as in the control group.

The feces were collected daily at the same time (morning and evening), weighed and ground in a mortar. At each collection, $50 \%$ of the homogenized mass was taken for analysis. The collected portions were stored in the refrigerator. After the end of the experimental (accounting) period in the collected feces, the initial moisture was determined by listening at $60-70{ }^{\circ} \mathrm{C}$ to constant weight. The resulting air-dry mass was thoroughly ground and sent for analysis [3].

After the completion of the basic physiological experiments, on a larger population of primates, in an open-air cage, the results were tested. For this, using the method of pairs of analogs, we conducted a selection of ma-as-rhesus, aged 7-15 years, in 3 aviaries, 12 animals per group. Aviaries were located at the same level, in the same microclimatic conditions.

The results were statistically processed using the GraphPad Prizm 8.0 software (USA) and expressed as arithmetic means and their standard errors. The statistical significance of the differences was determined using one-way analysis of variance with subsequent post hoc corrections for multiple comparisons using the Tukey and Sidak method. The accepted level of statistical significance is $\mathrm{p}<0.05$.

\section{Research results}

The study of blood is of great importance for the diagnosis of all changes in the body, both under the influence of external and internal factors. Therefore, the study of hematological parameters in experiments is attached to an important, scientific value table 2.

Of all the hematological parameters, the most important role in the body is played by the blood corpuscles. The main part of the formed elements are erythrocytes. According to the results of our study at the beginning of the experiment and at the end, the number of erythrocytes in all studied groups is within the limits of an insignificant increase relative to the physiological norm $\left(6.2\right.$ million per $\left.1 \mathrm{~mm}^{3}\right)$, with reliability $(\mathrm{p}<0.05)$. This pattern can be associated with the influence of external factors, namely, with a significant increase in the ambient temperature by the time the experiment starts. 
Table 2. Results of the general blood test of monkeys, $\mathrm{X} \pm \mathrm{Sx}$.

\begin{tabular}{|l|c|c|c|c|c|c|}
\hline \multirow{2}{*}{ Indicators } & \multicolumn{3}{|c|}{ At the beginning of the experiment } & \multicolumn{3}{c|}{ At the end of the experiment } \\
\cline { 2 - 7 } & control & 2-experiment & 3-experiment & control & 2 experiment & 3-experiment \\
\hline $\begin{array}{l}\text { Leukocytes, } \\
\text { x10 } / 1\end{array}$ & $9,82 \pm 1,65$ & $11,40 \pm 1,14$ & $10,01 \pm 1,21$ & $10,82 \pm 1,99$ & $12,36 \pm 3,12$ & $10,73 \pm 0,69$ \\
\hline Erythrocytes, x10 $12 / 1$ & $6,30 \pm 0,05$ & $6,45 \pm 0,24$ & $6,11 \pm 1,14$ & $6,43 \pm 0,17$ & $6,24 \pm 0,29$ & $6,39 \pm 0,20^{*}$ \\
\hline Hemoglobin, g/1 & $143,40 \pm 1,40$ & $143 \pm 1,41$ & $144,31 \pm 1,62$ & $145, \pm 0,5$ & $139,40 \pm 2,25$ & $145,20 \pm 3,19$ \\
\hline Hematocrit, 1/1 & $0,43 \pm 0,01$ & $0,43 \pm 0,01$ & $0,43 \pm 0,01$ & $0,43 \pm 0,00$ & $0,42 \pm 0,01 * *$ & $0,44 \pm 0,01$ \\
\hline $\begin{array}{l}\text { Average erythrocyte } \\
\text { volume, x10 } 15\end{array}$ & $67,80 \pm 0,42$ & $67,20 \pm 2,13$ & $68,00 \pm 0,65$ & $68,20 \pm 0,42$ & $68,00 \pm 2,50$ & $68,00 \pm 0,61$ \\
\hline $\begin{array}{l}\text { Average Hb content in } \\
\text { rrythrocyte, pg }\end{array}$ & $22,76 \pm 0,29$ & $22,28 \pm 0,79$ & $22,80 \pm 0,15$ & $22,84 \pm 0,30$ & $22,48 \pm 0,85$ & $23,06 \pm 0,26$ \\
\hline $\begin{array}{l}\text { Erythrocyte } \\
\text { nisocytosis, \% }\end{array}$ & $12,98 \pm 0,20$ & $12,74 \pm 0,31$ & $13,01 \pm 0,30$ & $13,22 \pm 0,29$ & $13,36 \pm 0,55$ & $13,26 \pm 0,37$ \\
\hline Platelets, x10 $/ 1$ & $308,40 \pm 18,15$ & $392 \pm 21,32$ & $298,11 \pm 19,21$ & $316, \pm 25,62$ & $362,20 \pm 23,53$ & $287,60 \pm 23,13$ \\
\hline $\begin{array}{l}\text { Average platelet } \\
\text { volume, fl }\end{array}$ & $9,74 \pm 0,19$ & $9,58 \pm 0,41$ & $9,81 \pm 0,21$ & $9,94 \pm 0,33$ & $9,94 \pm 0,53$ & $10,02 \pm 23,24$ \\
\hline ESR, mm / h & $0,89 \pm 0,11$ & $0,90 \pm 0,12$ & $1,10 \pm 0,23$ & $0,89 \pm 0,10$ & $0,80 \pm 0,22$ & $1,30 \pm 0,63$ \\
\hline
\end{tabular}

$\mathrm{p}<0.01^{* *}, \mathrm{p}<0.05^{*}$

The respiratory function of erythrocytes is inextricably linked with the properties of the hemoglobin protein they contain. Therefore, an important indicator is its level, which depends on the balance of the diet in terms of macro- and micronutrients, as well as on the functioning of the liver and hematopoietic organs. In our experiment, the research results indicate that the level of hemoglobin in the blood, before testing, is within the physiological norm. At the end of the experiment, as a result of the use of fishmeal, there is a slight increase in hemoglobin (HGB) in the experimental group in relation to the control by $0.14 \%$. In experimental group 2, the hemoglobin level is within the physiological norm. This may be due to the above physiological increase in the concentration of red blood cells in the blood.

The general functioning of the immune system in experimental primates was monitored by the level of leukocytes in the blood. As a result, it was found that at the beginning of the experiments, the level of leukocytes was within the normal range. But at the end of the experiment, there is a slight increase in the level of leukocytes, both in the experimental and in the control group, but a pronounced increase in indicators, nevertheless, is in the upper bounds of the reference values.

The percentage ratio of the volume of blood to be examined to the volume occupied by erythrocytes in it (hematocrit), and ESR, both at the beginning of the experiment and after the use of fishmeal and Bactistatin, are within the physiological norm.

When monitoring the state of ensuring hemostasis of the primate organism, attention was paid to the number of platelets in the blood. As a result, at the beginning of the experiment, the number of platelets in primates of the control group was within the reference values, from 200 to 400 billion / L. The results of blood tests at the end of the experiment indicate that in the experimental groups, from the use of fishmeal and Bactistatin, the number of platelets remained within the physiological norm.

Thus, the results of the experiment convincingly prove that as a result of the use of fishmeal and the probiotic complex Bactistatin, in the composition of granulated compound feeds, no critical increase or decrease in formed elements relative to the reference values was revealed. And, the use of the studied substances in feeding primates does not violate homeostasis. At the same time, it has a certain positive effect on the blood picture, expressed by more favorable changes in hematological parameters.

To control the usefulness of feeding primates, especially when using fishmeal in complete 
mixed feed, and to ensure prompt response to nutritional imbalances and adjustments in diets, the biochemical parameters of blood serum were determined. For a more complete display of metabolism in the blood serum, the following were determined: protein, glucose, calcium, phosphorus, bilirubin table 3 .

Table 3. Biochemical parameters of blood serum, $\mathrm{X} \pm \mathrm{Sx}$.

\begin{tabular}{|c|c|c|c|c|c|c|}
\hline \multirow{2}{*}{ Indicators } & \multicolumn{3}{|c|}{ At the beginning of the experiment } & \multicolumn{3}{c|}{ At the end of the experiment } \\
\cline { 2 - 7 } & control & 2-experiment & 3-experiment & control & 2-experiment & 3-experiment \\
\hline $\begin{array}{c}\text { Glucose } \\
\text { (mmol / })\end{array}$ & $4,43 \pm 0,44$ & $4,41 \pm 0,10$ & $3,97 \pm 0,34$ & $3,32 \pm 0,38$ & $2,86 \pm 0,33$ & $3,27 \pm 0,38^{*}$ \\
\hline $\begin{array}{c}\text { Bilirubin } \\
(\mu \mathrm{mol} / 1)\end{array}$ & $6,99 \pm 2,74$ & $2,82 \pm 0,33$ & $7,01 \pm 1,81$ & $6,98 \pm 1,47$ & $4,23 \pm 0,92$ & $7,17 \pm 1,47$ \\
\hline $\begin{array}{c}\text { Phosphorus } \\
\text { (mmol / })\end{array}$ & $1,17 \pm 0,19$ & $1,49 \pm 0,26$ & $1,09 \pm 0,13$ & $0,61 \pm 0,13$ & $0,80 \pm 0,2$ & $0,65 \pm 0,11$ \\
\hline $\begin{array}{c}\text { Calcium } \\
(\mathrm{mmol} / 1)\end{array}$ & $2,56 \pm 0,06$ & $2,41 \pm 0,04$ & $2,13 \pm 0,14$ & $2,01 \pm 0,16$ & $2,38 \pm 0,12$ & $2,04 \pm 0,13$ \\
\hline $\begin{array}{c}\text { Protein } \\
(\mathrm{g} / \mathrm{l})\end{array}$ & $89,31 \pm 8,40$ & $92,06 \pm 3,55$ & $82,98 \pm 4,11$ & $80,12 \pm 1,66$ & $77,25 \pm 4,2$ & $82,73 \pm 1,34$ \\
\hline
\end{tabular}

$\mathrm{p}<0.05^{*}$

To assess the functions of the endocrine system and control the state of carbohydrate metabolism in primates, the blood glucose level was determined. At the beginning of the experiment, the glucose level was within the physiological norm. But at the end of the experiment, in experimental groups 2 and 3, after the use of bactistatin and fishmeal in the structure of rations, the glucose level slightly decreased by $16-1.5 \%$, with a confidence level of $\mathrm{p}<0.05$, but was within the physiological norm.

Bilirubin is a bile pigment; at the beginning of the experiment, its level was lower in the experimental group than in the control group and in the experimental group, but it was in the lower normal range. At the end of the experiment, the level of bilirubin in experimental group 2 approached the physiological norm. In the 3rd experimental group, it changed slightly upward, relative to the control group by $2.6 \%$, but at the same time it was within the physiological norm.

The level of calcium and phosphorus in the blood of the experimental groups, at the beginning of the experiment, was within the reference values. By the end of the experiment, there was also a slight deviation, relative to the reference values.

The analysis of protein metabolism showed that at the beginning and at the end of the experiment, there was not a significant fluctuation in indicators relative to the norm, which indicates a positive effect of chlorella on the primate organism, is an indicator of good health and proper metabolism.

Daily counting of feed consumed by primates and the analysis of their chemical composition made it possible to establish the amount of nutrients consumed per day. And the accounting of feces and its chemical composition made it possible to determine the amount of digested nutrients and to establish the digestibility coefficient.

On the basis of the research results, it was found that the best indices, in terms of digestibility, of most of the standardized organic substances, were noted in rhesus monkeys of the experimental groups. Table 4

Table 4. Digestibility of nutrients, $\%(X \pm S x)$.

\begin{tabular}{|c|c|c|c|}
\hline Indicators, \% & 1-Control & 2-Eperimental & 3-Experimental \\
\hline Crude protein & $65,34 \pm 1,04$ & $66,31 \pm 2,08$ & $71,00 \pm 1,14$ \\
\hline Crude fat & $38,09 \pm 0,98$ & $39,80 \pm 2,51$ & $42,01 \pm 1,85^{* *}$ \\
\hline Crude cellulose & $23,01 \pm 1,01$ & $23,15 \pm 1,79$ & $30,13 \pm 1,26$ \\
\hline
\end{tabular}




\begin{tabular}{|c|c|c|c|}
\hline Crude ash & $41,58 \pm 0,88$ & $51,40 \pm 1,11$ & $53,63 \pm 1,03$ \\
\hline $\begin{array}{c}\text { Crude Nitrogen-free } \\
\text { extractives }\end{array}$ & $78,05 \pm 1,12$ & $78,94 \pm 1,91$ & $80,31 \pm 1,27$ \\
\hline Calcium & $44,37 \pm 1,94$ & $45,53 \pm 0,87^{*}$ & $49,14 \pm 1,18$ \\
\hline Phosphorus & $59,79 \pm 2,01$ & $59,98 \pm 0,31$ & $61,00 \pm 1,84$ \\
\hline
\end{tabular}

$\mathrm{p}<0.01^{* *}, \mathrm{p}<0.05^{*}$

The highest index of crude protein digestibility was noted in the 3rd experimental group, where, in the structure of the feeding ration, part of the feed was replaced with fishmeal, the protein was absorbed $8.66 \%$ more efficiently. Primates of the 2 nd experimental group, where the drug Bactistatin was used as a probiotic, here the coefficient of protein digestibility, in relation to the control group, was $1.48 \%$ higher. Crude fat from the diet was better absorbed by the primates of the 3rd experimental group; in relation to the control, the digestibility coefficient was $10.29 \%$ higher. The next, according to the assimilation of crude fat, were noted primates of the 2 nd experimental group, crude fat was digested and assimilated by $4.48 \%$ more efficiently than in the control group. Coefficients of digestibility of crude fiber were higher in the experimental groups by $1.00 \%$ and $30.90 \%$, respectively, than in the control.

Good indices for the digestibility of raw ash were also noted in the experimental groups. As indicated by the data in Table 4, the use of the probiotic complex made it possible to improve the digestibility coefficient in the 2 nd experimental group by $23.61 \%$. And in the 3 rd test group, the digestibility of crude ash was $28.90 \%$ higher.

The digestibility coefficients of BEV were higher in the 2-test group by $1.1 \%$, in the 3 test group by $2.89 \%$ than in the control group.

The assimilation of the macronutrient calcium and phosphorus was higher in the experimental groups. In $2^{\text {nd }}$ experimental group, calcium was assimilated more efficiently by $2.61 \%$, in $3^{\text {rd }}$ experimental group by $10.75 \%$. A similar pattern is observed for phosphorus. In $2^{\text {nd }}$ experimental group, phosphorus was absorbed better by $0.32 \%$, in $3^{\text {rd }}$ experimental group by $2.02 \%$.

An important indicator of the effectiveness of the use of fishmeal and probiotic is the cost of feed, which constitutes a significant amount in the structure of the prime cost of maintaining primates, about $70 \%$. The indicators of feed consumption are most pronounced when testing experiments on a large livestock, with an open-air cage keeping. The data obtained correlate with the results of physiological experiments, table 5.

Based on the live weight indicators, it can be seen that the male rhesus monkeys in the experimental groups were superior to their counterparts in the control group.

The overall gain for the experiment was the highest in the primates of the third experimental group, and it was 890 , which is $161 \%$ higher than in the control. A similar pattern can be traced in the second experimental group. Thus, in the second group, the gain for the experience was 620 years and was higher, respectively, by $82 \%$ with a high degree of reliability $(\mathrm{p}<0.001)$.

Table 5. Feed costs per 1 head. for experiment.

\begin{tabular}{|c|c|c|c|}
\hline \multirow{2}{*}{ Indicators } & \multicolumn{3}{|c|}{ Groups } \\
\cline { 2 - 4 } & control & $2^{\text {nd }}$ & 3rd \\
\hline Live weight, kg: & & & $8,36 \pm 0,45$ \\
\hline at the beginning & $11,61 \pm 0,55$ & $9,30 \pm 0,36$ & $9,25 \pm 0,40$ \\
\hline At the end & $11,95 \pm 0,50$ & $9,92 \pm 0,49$ & $0,89 \pm 0,25^{*}$ \\
\hline Experiment gain, kg & $0,34 \pm 0,33$ & $0,62 \pm 0,19 * *$ & 261 \\
\hline \% to control & 100 & 182 & \\
\hline
\end{tabular}




\begin{tabular}{|c|c|c|c|}
\hline \multicolumn{1}{|l|}{ Costs for 1 head } & & & \\
\hline $\mathrm{Mj}$ & 3724,0 & 2070,5 & 1434,6 \\
\hline \% to control & 100 & $-44,40$ & $-61,48$ \\
\hline Crude protein, kg & 75,04 & 43,28 & 35,92 \\
\hline \% to control & 100 & $-42,33$ & $-52,13$ \\
\hline
\end{tabular}

$\mathrm{p}<0.05^{*}, \mathrm{p}<0.001^{* *}$

The data in Table 5 indicate that the use of fishmeal and bactistatin in the composition of diets had a positive effect on the efficiency of feed use by experimental animals. Male rhesus monkeys of all groups consumed the same amount of food and nutrients per head per day, but for the resulting gain in body weight, the costs were lower in the experimental groups. Fishmeal and bactistatin have a positive effect on the costs of metabolic energy and crude protein. The lowest costs of metabolic energy and crude protein are observed in the third experimental group. Energy consumption here was $61.48 \%$ lower, crude protein $52.13 \%$ lower. In the second experimental group, the costs of metabolic energy and crude protein were lower by $44.40 \%$ and $42.33 \%$, respectively.

Thus, the inclusion of fishmeal and bactistatin in the structure of the diet of male rhesus monkeys increases the growth by $10.64 \%$ and $6.67 \%$, respectively. At the same time, it helps to reduce the consumption of nutrients and feed per head.

\section{Conclusion}

The results of the conducted studies have convincingly shown that feeding the primates during the period of the experiments was balanced and scientifically grounded, with the observance of the frequency of feeding. A correlation was established between the use of the probiotic Bactistatin, during the period of the experiments, with the improvement of the intestinal microbiota, programming the metabolic activity of the intestinal symbiotic microbiota. As confirmed in the experiment, the better dynamics of digestibility, nutrients of the feeding ration. And the adjustment of feeding rations, including fishmeal in its structure, as a source of animal feed, made it possible to balance the nutritional value of the diet in terms of macro- and micronutrients, which in turn had an effect on improving the digestibility of feed, increasing the digestibility coefficients, while reducing the cost of nutrients to maintain physiological needs of the organism of primates and allowed to reduce the cost of produced, complete feed. The use of a probiotic complex for the formation of intestinal microbionts and fishmeal for balancing macro- and micronutrients, in both experiments, made it possible to increase the health level of monkeys, which is confirmed by hematological and biochemical blood tests, the studied parameters, which were within the physiological norm. Strongly confirming that the formation of symbiotic microflora and the provision of optimal, balanced levels of macro- and micronutrients in primates' diets and bodies are key to healthy eating and profitable primate management.

\section{References}

1. M.Yu. Volkov, News of higher educational institutions, North Caucasian region, Natural Sciences, Special issue, 23-26 (2008)

2. N.V. Gaponov, L.N. Gamko, Veterinary science, animal husbandry and bio-technology, 1, 85-93 (2021) doi: 10.36871 / vet.zoo.bio.202101011

3. N.V. Gaponov, Feed production, 1, 42-48 (2021) 
4. N.V. Gaponov, L.N. Gamko, T.N. Lenkova, Bulletin of NSAU (Novosibirsk State Agrarian University), 4(57), 65-72 (2020) doi: 10.31677 / 2072-6724-2020-57-4-65-72

5. N.V. Gaponov, Collection of scientific works of the Krasnodar Scientific Center for Animal Science and Veterinary Medicine, 9(1), 143-148 (2020) doi: 10.34617 / 02f8d850

6. N.V. Gaponov, Patent No. 2733291 dated October 01, 2020. Application No. 2019144389

7. A.P. Kalashnikov, Norms and rations of feeding agricultural animals: a reference guide, 456 (M., 2003)

8. E.I. Lebedev, Complex use of raw materials in the food industry, (M., Food. industry, 1992)

9. M.E. Murray, S. Chebatarev, The healing power of food, 640 (Rostov on Don, Phoenix, 1997)

10. A.I. Ovsyannikov, Fundamentals of experimental work in animal husbandry, 304 (M., Kolos, 1967)

11. V.M. Poznyakovsky, O.A. Ryazanova, T.K. Kalenik, V.M. Datsun, Expertise of fish, fish products and non-fish objects of water industry. Quality and safety, 331 (Novosibirsk, Sib. univ. publishing house, 2005)

12. B.A. Shenderov, Metamorphoses, 5, $72-80$ (2014)

13. B.A. Shenderov, Bulletin of Restorative Medicine, 3, 9-17 (2009)

14. B.A. Shenderov, Herald of restorative medicine, 102-106, 386-390 (2013)

15. D.A. Leukocytes, Stain Techn, 40, 333-338 (1965)

16. N.V. Gaponov, O.P. Neverova, O.V. Gorelik, A.V. Stepanov, E3S Web of Conferences, (DAIC 2020), 02006 (2020) https://doi.org/10.1051/e3sconf/202022202006

17. J.C. Jimenez-Chillaron, R. Duaz, D. Martinez, Biochimie, 94, 2242 -2263 (2012)

18. Y. Masumura, Journal gerontology, 26, 3 (1971)

19. R.D. Miles, F.A. Chapman, The benefits of fish Meal in Aquaculture diets

20. N.C. Pearson, Semin Thromb Hemost, 23(5), 433 -9 (1997)

21. B.A. Shenderov, Anaerobe, 17, 490 -495 (2011)

22. University of Florida, USA. 31.07.2006 URL: http:// www.thefishsite.com/articles/200/the-benefits-of-fish-meal-in-aquaculture-diets 